\title{
Expanding PVL positive MRSA healthcare-associated infections outbreak in a newborns unit, caused by hospital hygiene shortcomings
}

\author{
Elena-Carmina Drăgulescu ${ }^{1 *}$, Mihaela Oprea ${ }^{2}$, Cătălina Zorescu³ ${ }^{3}$ Roxana \\ Şerban ${ }^{4}$, Irina Codiţă ${ }^{1,5}$ \\ 1. Nosocomial Infections and Antibiotic Resistance Laboratory, "Cantacuzino" National Medico- \\ Military Institute for Research and Development, Bucharest, Romania \\ 2. Molecular Epidemiology Laboratory, “Cantacuzino” National Medico-Military Institute for \\ Research and Development, Bucharest, Romania \\ 3. Suceava Public Health Directorate, Romania \\ 4. National Institute of Public Health Bucharest, Romania \\ 5. Department of Microbiology, "Carol Davila" University of Medicine and Pharmacy Bucharest,
} Romania

\begin{abstract}
A prolonged outbreak of Healthcare-Associated Infections (HCAIs) evolved since December 2013, in a Newborns Unit from Hospital A, sited in the North-Eastern development region, Romania. A first cluster consisted of 19 cases, of which 18 infections in newborns and 1 labour infectious complication in a mother. Except for five cases declared and treated in the Neonatology Unit as hospital-acquired infections, the other cases were discharged and further required rehospitalisation and treatment.

Eight of these innitialy discharged cases were readmitted to the Pediatric Surgery Unit and two others to the Pediatrics Unit of Hospital B, while three others were readmitted to three hospitals: one to the Pediatrics Unit of Hospital C, and other two to Hospital A and Hospital D, respectively. The mother with the labour infectious complication was readmitted to the Gynecology Unit of the Hospital A.

A number offifteen Staphylococcus aureus (S. aureus) strains isolated from the HCAI first episode and 8 strains from 7 HCWs were received by „Cantacuzino” Institute, Nosocomial Infections and Antibiotic Resistance Laboratory from the County Public Health Directorate, for confirmation and molecular typing.

After a first round of interventions for infection control, a second episode bursted in Hospital A and our laboratory received six other $S$. aureus isolates from newborns, hospital environment, and HCWs.

Public Health interventions based on epidemiologic data and molecular microbiology results were finally successful. The evolution of all cases was favorable.
\end{abstract}

*Corresponding author: Elena-Carmina Drăgulescu, Nosocomial Infections and Antibiotic Resistance Laboratory, "Cantacuzino" National Medico-Military Institute for Research and Development, Bucharest, Romania. E-mail: elena_dragulescu@yahoo.com 
An important factor favoring the outbreak was the moving of the Birth Unit of Hospital A to an innapropriate location for an 18-month interval, more than innitially estimated, in relation to rehabilitation of the ward.

We considered to report this episode taking into account the unusual evolution, the risk of multiresistant bacterial strains spreading, and multiple unwanted consequences caused by shortcomings in providing appropriate hygiene conditions.

Keywords:MRSA, lukS/F-PV genes, spa type t008, HCAI outbreak, newborns unit, hospital hygiene

Received: $11^{\text {th }}$ April 2018; Accepted: $1^{\text {st }}$ October 2018; Published: $7^{\text {th }}$ October 2018

\section{Introduction}

According to the World Health Organization (WHO), "Healthcare-Associated Infection (HCAI), also referred to as "nosocomial" or "hospital" infection, is an infection occurring in a patient during the process of care in a hospital or other healthcare facility which was not present or incubating at the time of admission. HCAI can affect patients in any type of setting where they receive care and can also appear after discharge. Furthermore, they include occupational infections among staff." Particular risk factors like low birth weight, gestational age, length of stay pending on different associated pathologies and instrumentation are recognized in Newborn Intensive Care Units (NICUs) (1).

Newborn skin layer microstructure differs from adult skin, and particular pre-term, postterm and term skin changes are common in the first month of life adaptation period. There are physiological dermatological phenomena that occur, including newborns erythema, milia papules, miliaria, neonatal acne, sebaceous hyperplasia, non-infectious vesicopustular lesions, etc. The newborn skin is very susceptible to infection (2).

\section{Descriptive epidemiology of the first New- borns Unit outbreak}

Hospital A has 460 beds and functions in two different locations at $2 \mathrm{~km}$ from each other.

The Hospital Maternity is a medium sized one, with a Neonatology Unit of 30 beds and an Obstetrics/ Gynaecology Unit with 50 beds.
It is sited in a monoblock building, dating since 1983, and it covers the second-largest territory of the county and a population of 155061 people, of which 61495 in the urban area and 93566 in the rural area.

In the August 2012 - November 2013 interval, the Maternity was refurbished in the frame of a World Bank Program. During this interval, the Maternity functioned in the space of the Gynaecology ward, which was temporarily merged with the Surgery ward. The operating license was delivered by the County Public Health Authority under strict clauses, because of surface, space partitioning, and problems with functional flows. The Modernized Maternity reopened on December 4th 2013.

Sporadic detection of $S$. aureus on environment surfaces and newborns skin was reported with the occasion of the 9 salubrity tests performed during the August 2012 - November 2013 interval.

The incidence of nosocomial infections reported in the Newborns Unit was low (0.8-0.9\% of hospital discharged newborns). However, in the last three years all infections have been skin infections, which may suggest some problems in newborn care procedures, despite the fact that specific procedures are in place for both healthy and premature newborn care, hand washing and antisepsis, cleaning and disinfection and TB vaccination.

A first cluster of HCAI evolving in Hospital A consisted of 19 cases, of which 18 infections in 
newborns and 1 labour infectious complication in a mother. On December 16th 2013, the epidemiologist from Hospital B, which is the County Emergency Hospital, reported the admission to the Paediatric Surgery Unit of 3 newborns (cases 2, 3, 4), aged 12 to 17 days, all born in Hospital A. All of them presented with skin infections, required surgery and were diagnosed with Methicillin-Resistant $S$. aureus (MRSA) infection. The retrospective study of patients records revealed another previous case (case 1), aged 17 days, admitted to the same ward on November 19th, with a clinical diagnosis of left breast abscess.

On December 17th 2013, a team coordinated by the senior epidemiologist from the County Public Health Directorate point of work, sited in Hospital A city started the epidemiological investigation and took the first microbiological samples from the Maternity.

A major risk factor for infections in newborns was considered to be the lack of warm water caused by the breakdown of a water pump in the very day of moving to the new location, which was not resolved until after two weeks. During this interval, the toilet of the newborns was accomplished by using wet wipes.

On December 17th 2013, two other newborns coming from the Hospital A Maternity with the diagnosis of breast abscess/ staphylococcal skin infection, were admitted to Hospital B - Paediatric Surgery ward (cases 5 and 6). The expansion of the outbreak led the local public health authorities to decide on the temporary closure of Hospital A Maternity starting December 18th 2013. On the same day, two new cases (7 and 11) were hospitalized in Hospital B with staphylococcal skin infection. The decision was communicated to the Ministry of Health and local authorities.

A number of 8 mothers and their healthy newborns were then transferred from Hospital A to Hospital B, being sampled for detection of contamination/ colonisation with S. aureus. Cases with positive results for MRSA received prophylactic antimicrobial therapy, according to antimicrobial susceptibility testing results. Finding of MRSA colonisation in all transferred newborns indicated a strong $S$. aureus dissemination in Hospital A Maternity. Infection cases with onset in the new location led the investigation team to the hypothesis that the source of infection would be represented by healthcare workers (HCWs), which was confirmed by the high number of $S$. aureus nose or pharyngeal carriers in Maternity staff members, i.e. 22 persons $(35.5 \%)$.

On Public Health County Authority request, Hospital C, sited in the same city as Hospital A, reported details on case 10 , admitted to the Paediatric ICU ward since December 4th 2013, with the diagnosis of pleural and lung infection with MRSA. The onset was 2 weeks before and the case was born in Hospital A Maternity on October 25 th 2013 . The case was considered as part of the same outbreak based on epidemiological criteria.

Cases 17 and 18 were admitted to the Paediatric Surgery ward, Hospital B on 26th and 29th of December, respectively, with skin abscesses caused by MRSA.

A parent call then announced the admission of his 14-day-old son to the Paediatric ward of Hospital D, sited in another city of the same county (case 19). The patient record mentioned the following diagnoses: staphylococcal skin infection, breast abscess, umbilicus granuloma.

\section{Public health interventions}

On December 20th 2013, a team of 4 sanitary inspectors evaluated the activity and hygiene conditions in Hospital A Maternity and applied a contraventional penalty for nonconformities found.

The epidemiologist from the Hospital Infection Control Service had delivered a minutes informing the Hospital management about pos- 
sible shortcomings in newborns hygiene and the onset of several skin infections, but the Public Health Authority had not been asked for advice and methodological support.

Several nonconformities in respecting the refurbishing project were reported, as changing the destination of a room for nurses which was transformed into a room for washing and sterilisation of the instruments, thus causing unacceptable circuit breaks, and storage in the same room of euro pallets for waste collection. Remedies were taken.

Concomitantly, several other HCAI cases were detected, recorded in the patient observation sheets, but not reported. Thus, records of HCAI cases were belatedly drafted and included in the official reports of the Hospital for cases 8 , $9,12,13,14,15$, and 16 .

Another finding of the inspection team was that many of the discharged newborns were mentioned with toxic or allergic erythema diagnosis on the discharge record: 59 cases in October, 43 cases in November, though the newborns were discharged very quickly, without being vaccinated for TB. The Chief neonatologist explained that these manifestations were normal and in his opinion did not represent a concerning situation.

After closing the ward, daily nebulization was done, with 3 alternative disinfectant types.

On December 22nd 2013, a first repeat of the microbiological environment control was performed, sampling a number of 38 air probes and 47 salubrity tests. All samples were negative, except 2 surfaces that proved positive for MRSA.

On December 23rd 2013, all HCWs underwent an evaluation test on cleaning, disinfection, and sterilisation.

All procedures of daily cleaning and disinfection were repeated and a new bacteriological control was performed on December 31st 2013. All samples proved negative.
On the same day, all 22 S. aureus carriers detected previously were sampled again, after a first round of therapy. Eight of them remained carriers and were advised to follow a new round of treatment. On January 24th 2014 no staff member was found to carry $S$. aureus.

On January 6th 2014 reopening of the Hospital A Maternity was decided based on accomplishing all recommended actions, negative environment controls and no reporting of other newborn infection cases.

During the outbreak investigation, 42 MRSA and MSSA strains were sent to the Iași Regional Public Health Centre, which confirmed MRSA by phenotypic methods (MRSA PBP2 latex test).

Microbiological investigation in the Reference Centre for Staphylococci/ Nosocomial Infections and Antibiotic Resistance Laboratory was done in the December 2013 - May 2014 interval.

\section{Material and methods}

\section{Bacterial isolates}

Fifteen $S$. aureus strains isolated from the HCAI first episode and 8 strains from 7 HCWs were received for confirmation and typing at the Reference Centre for Staphylococci/ Nosocomial Infections and Antibiotic Resistance Laboratory, "Cantacuzino" Institute. A single strain was selected per patient, but 2 patients presented 2 strains isolated from 2 different body sites (umbilical stump and skin). One HCW presented 2 different strains (1139-A and 1139-B) in the same biological probe (pharyngeal exudate) (Table 1).

From the second episode, six $S$. aureus strains were received for confirmation, typing and comparing with strains from the first episode (Table 1). 
Table 1. Distribution of $S$. aureus strains by sampling site

\begin{tabular}{|c|c|}
\hline Hospital samples & Number of isolates (isolate ID) \\
\hline \multicolumn{2}{|c|}{ First episode } \\
\hline Umbilical stump & $4(1122,1124-\mathrm{A}, 1127-\mathrm{A}, 1128)$ \\
\hline Nasal swabs (HCWs) & $2(1133,1134)$ \\
\hline Pustules & $1(1132)$ \\
\hline Skin & $7(1120,1124-\mathrm{B}, 1125,1127-\mathrm{B}, 1129,1130,1131)$ \\
\hline Abscess pus & $2(1121,1123)$ \\
\hline Lochia & $1(1126)$ \\
\hline Pharyngeal exudates (HCWs) & $6(1135,1136,1137,1138,1139-\mathrm{A}, 1139-\mathrm{B})$ \\
\hline \multicolumn{2}{|c|}{ Second episode } \\
\hline Abscess pus & $2(1305,1306)$ \\
\hline Baby changing radiant table in the birthing room & $1(1307)$ \\
\hline Gynaecological examination table in the birthing room & $1(1308)$ \\
\hline Nasal swabs (HCWs) & $2(1309,1310)$ \\
\hline
\end{tabular}

\section{Cultivation and characterization of the isolates}

The isolates were cultivated on Columbia Blood Agar Base (Oxoid) with 7\% sheep blood and Mannitol salt agar (Oxoid) and incubated at $35 \pm 2{ }^{\circ} \mathrm{C}$ for $18-24 \mathrm{~h}$. Characteristic colonies were identified using standard phenotypic (including automated Vitek2, BioMerieux, France) and molecular microbiological methods. Triplex PCR for $n u c, l u k S / F-P V$ and mecA genes was performed using an optimized "in house" protocol (3).

Antibiotic susceptibility testing was performed by Kirby-Bauer disk diffusion method, according to the EUCAST standard v. 3.1 (4), and 4.0 (5) to a set of 15 antibiotics, using the S. aureus ATCC 29213 quality control reference strain. Vancomycin was tested by broth micro dilution method using the same quality control reference strain. The double-disk diffusion test for detecting inducible resistance to Macrolides, Lincosamides and Streptogramins B (D-test) was performed as described by Leclercq, 2002 (6).

Total genomic DNA from $S$. aureus strains used in all PCR reactions was obtained by thermal and enzymatic lysis method (lysostaphin $1 \mathrm{U} / \mu \mathrm{L}$, proteinase $\mathrm{K} 2 \mathrm{mg} / \mathrm{mL}$ ).
Detection of mecA, lukS/F-PV genes was performed by the previously mentioned triplex PCR protocol and simplex PCR protocols were used for exfoliative toxins (eta, etb), toxic shock syndrome toxin 1 (tst 1 ), benzylpenicillin (blaZ encoding beta-lactamases responsible for resistance against penicillins), erythromycin-clindamycin $[\operatorname{erm}(\mathrm{A}), \operatorname{erm}(\mathrm{C})$ - encoding for methylases responsible for resistance against macrolides and clindamycin], gentamicin (aacA-aphD - encoding for a bifunctional aminoglycoside modifying enzyme), tetracycline $[\operatorname{tet}(\mathrm{K}), \operatorname{tet}(\mathrm{M})-$ responsible for tetracycline resistance] genes.

Sequences of primers used in triplex/ simplex PCR reactions and the cycling conditions were described in a previously published article (3). The PCR reactions were performed using an Applied Biosystems or a Corbett Research Thermocyclers.

The following reference strains were used as controls: 33/ 2009 strain (Nosocomial Infections Laboratory Collection) for $n u c, l u k \mathrm{~S} / \mathrm{F}-$ $\mathrm{PV}$, mecA genes; IC13456 strain (for eta gene); IC13455 strain (for etb gene); IC13454 strain (for $t s t$ gene); 5681/ 2010 strain (Nosocomial Infections Laboratory Collection) for blaZ, er$m(\mathrm{C}), \operatorname{aac} \mathrm{A}-\operatorname{aph} \mathrm{D}, \operatorname{tet}(\mathrm{K})$ genes; 39/ 2008 strain 
(Nosocomial Infections Laboratory Collection) for $\operatorname{erm}(\mathrm{A})$ and tet(M) genes.

The PCR products were migrated by agarose $(1.5 \%$ and $2 \%)$ gel electrophoresis, stained with ethidium bromide $10 \mathrm{mg} / \mathrm{mL}$ and visualized in an UV transilluminator.

SCCmec typing was performed by multiplex PCR according to the scheme proposed by Milheirico et al., 2007 (7). The following S. aureus reference strains were used as controls: COL (SCCmec type I), BK2464 (SCCmec type II), ANS46 (SCCmec type III), MW2 (SCCmec type IVa), WIS (SCCmec type V), HDE288 (SCCmec type VI).

Detection of polymorphism in the $\mathrm{X}$ region of the staphylococcal protein A (spa) gene (spa-typing) was carried out as described by Harmsen et al., 2003 (8) using the forward primer spa-1113f: 5'TAAAGACGATCCTTCGGTGAGC3' and the reverse primer spa-1514r: 5'CAGCAGTAGTGCCGTTTGCTT3'.

Finding of the spa repeat code and classification of strain into the spa types were done using the Ridom StaphType software v. 2.2.1 (Ridom $\mathrm{GmbH}$, Wurzburg, Germany) and synchronized in the Ridom SpaServer (www.spaserver.ridom. de). The spa clonal complexes (spa-CC) were deduced using the Based Upon Repeat Pattern algorithm (BURP).

Pulse Field Gel Electrophoresis (PFGE) was performed using the "gold standard" method previously described by Murchan et al., 2003 (9). S. aureus NCTC 8325 was used as size marker to allow later normalization of electrophoretic patterns across the gel. The digital image was stored electronically as TIFF file and analyzed with the BioNumerics 6.6 (Applied Maths) software using the Dice coefficient and UPGMA method with $1.5 \%$ tolerance and $1.5 \%$ optimization settings. A similarity cut-off of $80 \%$ (2 different bands) and the criterion of a difference of no more than 6 bands as described by Tenover et al., 1995 were used to define a pulsotype (10).

\section{Results}

All the strains proved nuc gene positive, except one (1310 strain) identified as Staphylococcus haemolyticus using the Vitek2 system. The origin of strains by sample and their PFGE, spa, SCCmec types and the presence of lukS/ F - PV genes are presented in Figure 1.

All the strains proved negative for the exfoliative toxins A and B (eta, etb), the toxic shock syndrome toxin 1 ( $t s t$ ), aminoglycosides ( $a a-$ $c \mathrm{~A}-a p h \mathrm{D})$, and tetracycline $[\operatorname{tet}(\mathrm{M})]$ genes. The 1124-B strain was positive for $\mathrm{erm}(\mathrm{C})$ gene, and the 1133 strain was erm(A) gene positive. At a similarity index of $80 \%$ between the band profiles obtained in the PFGE analysis ten pulsotypes designed A-J and three subtypes (D1 and D2; E1 and E2; G1 and G2) were distinguished.

Seven strains isolated from 6 newborns and a HCW nasal swab from the first episode and four strains isolated from abscess pus (2 strains), baby changing radiant table and gynaecological examination table in the birthing room from the second episode classified as PFGE pulsotype A (100\% similarity index, 0 difference bands which demonstrates their clonality), with the same antibiotic resistance pattern $\mathrm{P}, \mathrm{FOX}, \mathrm{E}, \mathrm{K}$, spa type t008, SCCmec IV type, and blaZ, mecA, lukS/F$\mathrm{PV}$ genes positive; one strain isolated from the labour associated infection (lochia) and two strains from the skin of two newborns classified as PFGE pulsotype D subtype D1 (100\% similarity index, 0 difference bands which demonstrates their clonality), spa type t015, blaZ gene positive, resistant to $\mathrm{P}$; two strains isolated from newborn umbilical stumps from the first episode classified as PFGE pulsotype G, subtype G1 (100\% similarity index, 0 difference bands which demonstrates their clonality) and one strain from a HCW nasal swab from the second episode classified as PFGE pulsotype G, subtype G2 (86\% similarity index with subtype G1, 3 difference bands which proves they are close- 
ly related), with antibiotic resistance pattern $\mathrm{P}$, FOX, K, spa type t002, SCCmec IV type and blaZ, mecA genes positive; one strain from the pharyngeal exudate of a $\mathrm{HCW}$ and two strains from newborns' skin classified as PFGE pulsotype E, subtypes E1 or E2 (91\% similarity index, 2 difference bands which proves they are closely related), antibiotic resistance pattern $\mathrm{P}$, FOX, E, DA (MLSBi), K, TE/ TE(I), QD, spa type t127, SCCmec IV or IVE types and blaZ, $m e c \mathrm{~A}, \operatorname{erm}(\mathrm{C})$ and $\operatorname{tet}(\mathrm{K})$ genes positive. A strain belonging to this cluster was positive for $l u k \mathrm{~S} / \mathrm{F}$ PV genes. PFGE clusters dendrogram of the $S$. aureus isolates is presented in Figure 1.

\section{Discussion}

Staphylococcus aureus is a bacterium that commonly colonizes the skin and mucosal surfaces of many mammalian and avian species, but it may become a challenging and costly cause of skin and soft-tissue infections (SSTIs), endovascular infections, pneumonia, septic arthritis, endocarditis, osteomyelitis, foreign-body infections, sepsis, especially in immunocompromised patients and toxinoses, most frequently food poisoning with preformed Staphylococcal Enterotoxins (SEs). The nasal cavity is the most epidemiologically important site for colonization in humans, and estimates of prevalence of permanent nasal carriage of $S$. aureus by people are of $20 \%$ to $30 \%$ (11).

Under antibiotic pressure, but also as a measure of adaptation to various environmental conditions, $S$. aureus has changed its chromosomal structure by mutation or horizontal gene transfer and has become multidrug resistant and virulent.

In a healthcare facility, the sources of infection and of the preceding contamination may be the staff, the infected or colonized patients, household members and other visitors, or the in-

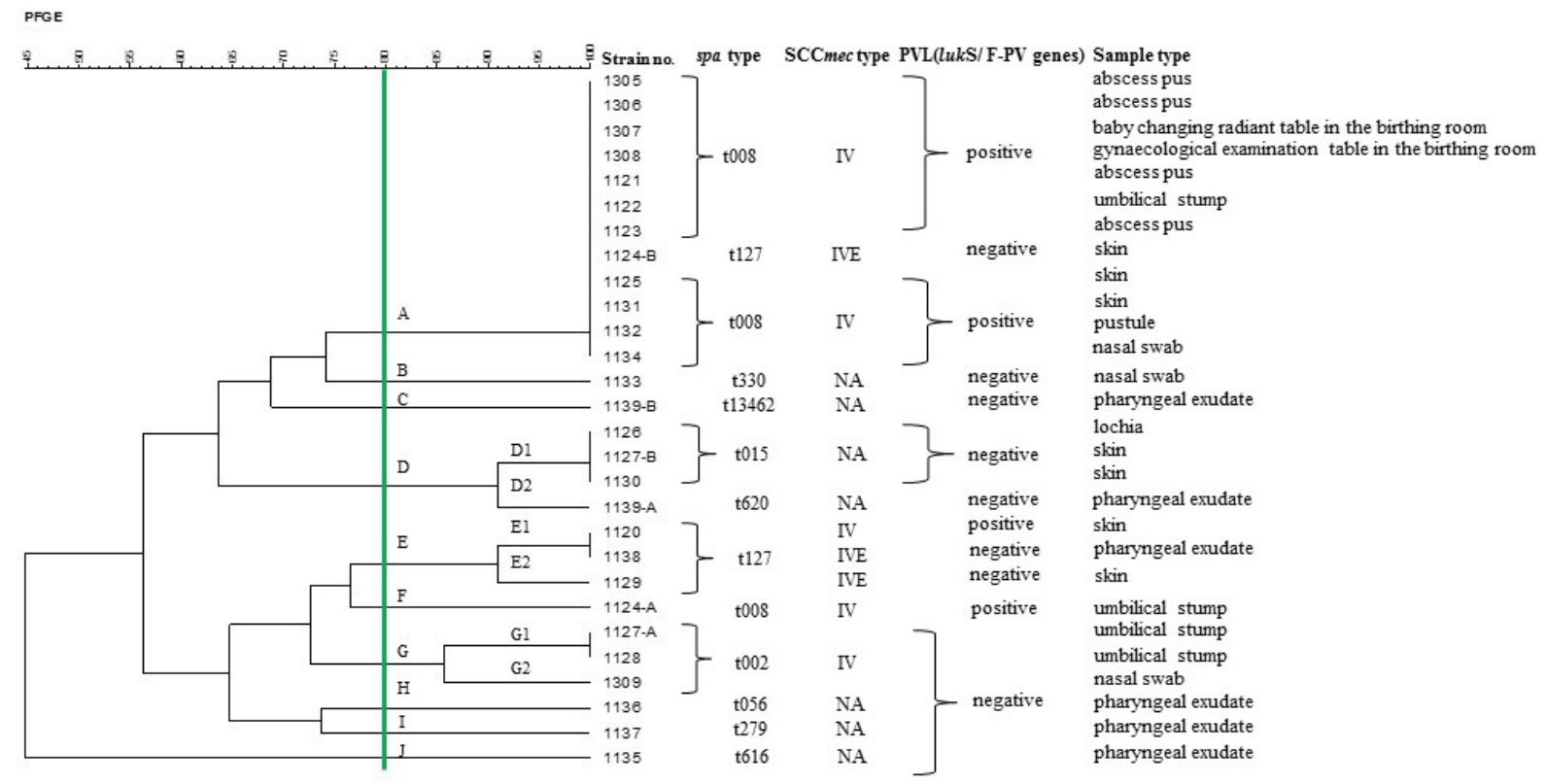

Fig. 1. PFGE clusters dendrogram of the $S$. aureus isolates from the first and second episodes analyzed using BioNumerics software v. 6.6 (Applied Maths). The predominant strains of the outbreak were framed in the PFGE pulsotype A (100\% similarity index, 0 difference bands) with $s p a$ type $\mathbf{t 0 0 8}$, positive for $l u k \mathrm{~S} / \mathrm{F}$ PV genes. 
animate environment. The hospital environment may be contaminated with multidrug resistant or virulent pathogens. Personal protective equipment (PPE) may become contaminated with potential pathogens after care of a patient colonized or infected with an infectious agent (12).

According to Albrich and Harbarth, transmission of MRSA from staff to patients was demonstrated by genotyping in 63 of 68 studies (93\%) and MRSA eradication was successful in 449 of 510 healthcare staff (88\%) (13).

During general care and/ or medical treatment, the hands of HCWs often come in close contact with patients. The hands of the clinical staff are thus the most frequent vehicles for healthcare-associated infections, if hand hygiene is not performed before touching another patient. Transmission by this route is much more common than vector-borne or airborne transmission or other forms of direct or indirect contact. Rammelkamp et al. demonstrated that infants exposed to nurses who handled colonized newborns acquired $S$. aureus in $14 \%$ of cases and $43 \%$ of cases if good, respectively no handwashing was performed (14). The good compliance with hand hygiene is essential to prevent cross-transmission.

In his $\mathrm{PhD}$ thesis, Mernelius, demonstrated that transmission of $S$. aureus through air is not important, because no $S$. aureus was detected in the air (15).

However, Sherertz et al. recently supported the evidence of $S$. aureus outbreaks associated with skin colonization or viral upper respiratory tract infection by a phenomenon of airborne dispersal called the "cloud" phenomenon. Though airborne dispersal was insignificant with nasal breathing, counting, coughing 6 times, or sneezing once, moving produced large numbers of $S$. aureus in the air, most probablly dispersed from skin and clothing by friction and movement (16).

On the other hand, all objects that come in contact with patients should be considered po- tentially contaminated. Indirect contact transmission may include: patient-care devices (e.g., electronic thermometers, glucose monitoring devices) which may transmit pathogens if devices contaminated with blood or body fluids are shared between patients without cleaning and disinfecting between uses; shared toys may become a vehicle for transmitting pathogenic bacteria among paediatric patients; instruments that are inadequately cleaned between patients before disinfection or sterilization (e.g., endoscopes or surgical instruments) or that have manufacturing defects that interfere with the effectiveness of reprocessing may transmit bacterial pathogens (17).

The first essential measure in preventing the spread of healthcare-associated infections with MRSA is isolation of infected patients in order to reduce the spreading of pathogens.

Unit-based procedures, e.g. visitation, hand washing and nail care, skin and cord care, adequate maintenance of hubs in peripheral and central lines, correct cohorting and isolation procedures, appropriate use of antibiotics, and adequate unit design and staffing are recommended in order to minimize infectious risk in NICUs (1).

In 2013, Chan et al. found evidence supporting overall higher levels of early-onset neonatal infection in the newborns of mothers with bacterial infection or colonization compared to the newborns of mothers without infection or colonization, with seven times higher odds of early-onset neonatal infection in newborns of infected mothers compared to newborns of uninfected mothers (18).

In the present reported outbreak there is an unusually high rate of infant breast infections. Though usually uncommon, breast infections may be favoured by local hormonal conditions that may be present in this period of life, mostly in the second week of life, when neonatal breast tissue is still enlarged because of the maternal oestrogens (19). 
Until recently, MRSA infections presenting in the community were usually caused by healthcare-associated MRSA (HCA-MRSA) strains acquired directly or indirectly during previous hospital or healthcare contact (20).

Starting with the late 1990s, Community-Associated MRSA (CA-MRSA) strains were introduced from the community into hospitals, causing hospital-associated infections and outbreaks (21). Community based infection control strategies may still be helpful in stemming the influx of traditionally community-associated strains, particularly USA300, into the healthcare setting.

USA300 (t008/ ST8/ SCCmecIV) is the predominant, traditional CA-MRSA clone in the US that has rapidly disseminated and replaced USA400 (ST1 and spa types t127, t128 and t1178) since its isolation in 2000 and then spread worldwide (22).

The success MRSA clone USA300, susceptible to clindamycin, trimethoprim/ sulfamethoxazole and gentamicin, evolved initially in semi-closed collectivities and started to spread in hospital units in 2000 (23). The first infection caused by MRSA USA300 evolving in a NICU was reported in 2004 (24). This strain was involved in SSTIs and severe invasive infections like necrotizing pneumonia, osteomyelitis, septic arthritis, etc., because of its capacity to produce several virulence factors like Panton-Valentine leukocidin (PVL), exfoliative toxins etc. (22).

In infection control and healthcare epidemiology, the clinical microbiology laboratory plays a critical role, contributing to the prevention of infectious disease transmission in healthcare settings by promptly detecting and reporting epidemiologically important organisms, identifying emerging patterns of antimicrobial resistance, and assisting in the assessment of the effectiveness of recommended precautions to limit transmission during outbreaks (25). Laboratories are usually the first to recognize infection outbreaks.
The introduction of molecular typing methods, including Whole-Genome Sequencing (WGS) into epidemiological investigations has provided powerful new tools for tracking the origin and routes of dissemination of MRSA strains not only among patients in a hospital, but also among hospitals and community, in different countries or even across different continents (26). The "gold standard" to track bacterial transmission in healthcare settings has for long time been considered to be the Pulsed Field Gel Electrophoresis (PFGE), a method that is labour-intensive and relies on semi-subjective analysis. More discriminatory, Multi Locus Sequence Typing (MLST) is laborious and time-consuming, while molecular typing by sequencing of the hyper variable part of the $S$. aureus protein A gene (spa typing) has overcome these problems and has shown promising results in epidemiological investigations (15). Typing of Staphylococcal Chromosomal Cassette mec (SCCmec typing) may provide additional information on $S$. aureus geographical and temporal evolution.

The most disseminated HA-MRSA worldwide includes the ST239 lineage $(27,28)$, as well as the ST5 lineage (29). The most characterized CA-MRSA includes the ST8 lineage, such as ST8/ SCCmecIVa (USA300) (30), and also the lineages of ST30/ SCCmecIV, ST80/ SCCmecIV (31), and ST59/ SCCmecV (32). CA-MRSA mainly causes SSTIs, but also, occasionally, invasive infections, and often produces PVL (31) and exhibits elevated expression of cytolytic peptides (phenol-soluble modulins, PSMs; or $\delta$-hemolysin, Hld) (33).

CA-MRSA bacteria are much less prevalent in Europe, where the European ST80-IV CA-MRSA clone, USA300 CA-MRSA strains, and other lineages, such as ST22-IV, coexist. Infections with PVL-positive MRSA have been described in most European countries as Austria (34), Germany (35), Bulgaria (36), Spain 
(37), UK (38), Italy/ NICU (39), Belgium (40), France (41).

Romania is considered a "hot spot" for MRSA infections (42).

According to the report of the European Antibiotic Surveillance Network (EARS-Net) in Romania, the percentages of MRSA in invasive infections were $49.5 \%$ in $2011,53.3 \%$ in 2012 , 64.5\% in 2013 and 56\% in 2014 (http://ecdc.europa.eu/en/publications/Publications/antimicrobial-resistance-europe-2014.pdf).

Case reports on fatal sepsis due to PVL-positive CA-MRSA spa type t044 clone were presented in one study (43), and one communication (44) by Romanian authors. Over the time, PVL-positive t044 $S$. aureus strains have been involved in necrotizing pneumonia, fatal sepsis with community-onset, associated with influenza, but also with skin infections evolving in teenagers or pre-school children in Romania $(43,44)$.

Reported MRSA rates in hospitals are very high, ranging from approximately $30 \%$ up to $85 \%$, whereas CA-MRSA has been identified inside hospitals (45-56). S. aureus spa type t030 has been described as the prevalent MRSA spa type in Romania (57), being reported in several studies as the most widespread MRSA in Romanian hospitals $(50,58)$, and considered as being endemic (59). Second Seqnet.org structured survey (60) and other authors (61) reported the ST239 clone as the prevalent one. CA - S. aureus spa type t008 was reported in 2008, in one Romanian western county hospital (62). S. aureus spa type $\mathrm{t} 127$ has been reported frequently in Romanian hospitals starting with 2006 (58, 59, 63). This spa type was described also by Franco $\&$ al., in 2011 to be associated with animals (e.g., pigs) (64). Recently, three PVL-negative MRSA t127 strains, with the same PFGE pulsotype were isolated from newborn skin, from the bed frame and hospital air controls in one Bucharest hospital (unpublished data).
Monecke et al. published a study on clinical isolates recovered between 2008-2012 from bloodstream infections, SSTIs, as well as from screening swabs collected from several hospitals in Iași, the North-Eastern part of Romania. Isolates were characterised by microarray hybridisation and nearly half of all isolates (47\%), and about one third $(34 \%)$ of bloodstream isolates were MRSA. Thirty one percent (31\%) MRSA and $14 \%$ MSSA strains were positive for PVL genes (65).

In 2014, Scheithauer et al. published a report on a MRSA spa type t127 outbreak evolving a neonatology level III ICU. This spa type, extremely rare in Germany, proved to come from a HCW belonging to a group of recently employed Romanian HCWs, who was colonized with the spa t127 strain. All carriers were successfully decolonized. After this outbreak, a universal screening programme was implemented in the hospital, of all new employees, as part of infection control management strategy (66).

Molecular analysis of strains isolated in the present reported outbreak revealed a strong circulation of several $S$. aureus clones, some producing Panton-Valentine leukocidin, and cross-contamination of newborns, HCWs, a mother with a labour associated infection and the inanimate environment. Genotyping of $S$. aureus strains made possible the tracking of the sources and routes of transmission and evaluating the potential of pathogenicity and substantiated the public health interventions.

The predominant clone of the outbreak was MRSA t008/ PVL-positive/ PFGE pulsotype A/ $\mathrm{P}, \mathrm{FOX}, \mathrm{E}, \mathrm{K} /$ blaZ and mecA-positives/ SCCmecIV, followed by MSSA t015/ PVL-negative/ PFGE pulsotype D subtype D1/ P/ blaZ-positive and mecA-negative; MRSA t127/ PVL-negative or positive/ PFGE pulsotype E subtypes E1 or E2/ P, FOX, E, DA (MLSBi), K, TE or TE(I), QD/ blaZ, mecA, erm $(\mathrm{C})$, tet( $(\mathrm{K})$-positives/ SCCmecIV or IVE; MRSA t002/ PVL-negative/ PFGE 
pulsotype $\mathrm{G}$ subtypes $\mathrm{G} 1$ or $\mathrm{G} 2 / \mathrm{P}, \mathrm{FOX}, \mathrm{K} /$ blaZ and mecA-positives/ SCCmecIV.

Among the different interventions used to stop outbreak spreading, the most fruitful reported ones have been the implementation of improved hand hygiene, gloves and gowns for patient care, patient and staff decolonization (mupirocin intranasal ointment, bathing with antiseptics as povidone iodine, clorhexidine or hexachlorophene), isolation of colonized patients, cohorting of patients and nurses, staff training, etc. (67).

Laboratory based interventions like surveillance cultures for patients, staff and environment, molecular typing of strains, etc. are considered the most useful for identifying sources and ways of transmission and evaluating the intervention impact (68).

As there are no unanimously accepted guidelines, Gerber et al. published a consensus statement in 2006 on the prevention and control of MRSA colonization and infection, including, besides the aforementioned interventions starting with hand hygiene, cohorting and isolation, open communication between NICUs, collaboration with public health institutes, keeping strictly close to appropriate staffing and avoiding crowding of the newborn units (69).

\section{Conclusion}

We considered reporting this HCAI prolonged episode originating in a newborn unit, taking into account the unusual evolution, the risk of multiresistant bacterial strain spreading, and multiple unwanted consequences caused by shortcomings in providing appropriate hygiene conditions.

Though the outcome was favourable in all cases, observing hygiene regulations and avoiding shortcomings, earlier recognition of the outbreak using laboratory findings, along with prompt communication with public health institutions would result in fewer cases, with less financial expenses, and unwanted medical complications.

\section{Acknowledgements}

This study was supported by PN 092201 05, Project Manager Assoc. Prof. Irina Codiță; SIEG HG320/2013 and PN035-05, Programme Manager PhD Monica Străuț.

We acknowledge Professor Herminia de Lencastre for kindly providing us with the reference strains used for SCCmec typing, the Molecular Epidemiology Laboratory - "Cantacuzino" Institute colleagues for kind support, Olguța Nicoleta Drăcea (Corneli) PhD - "Cantacuzino" Institute Bacterial Culture Collection for kindly providing us with the $S$. aureus strains for eta, $e t b, t s t 1$ genes used as positive controls in the PCR reactions.

This publication made use of the spa typing website (http://www.spaserver.ridom.de/) that is developed by Ridom $\mathrm{GmbH}$ and curated by SeqNet.org (http://www.SeqNet.org/).

Results of this work were presented partially at the National Conference of Microbiology and Epidemiology, November 2014, Bucharest, Romania and are part of the doctoral thesis of E.C.D.

\section{Authors' contribution}

E.C.D. - study design and microbiological investigation, data analysis and interpretation, wrote the manuscript with support by I.C.

M.O. - data analysis and interpretation

C.Z. - field outbreak investigation and epidemiological report

R.S. - final epidemiological report and integration of microbiological information

I.C. - study design, integration of epidemiolog- 
ical data, contributed to the final version of the manuscript, final approval of the version to be published.

\section{Conflict of interest}

The authors declare that they have no conflict of interests.

\author{
Abbreviations \\ Staphylococcus aureus: S. aureus \\ Healthcare workers: HCWs \\ World Health Organization: WHO \\ Healthcare-Associated Infection: HCAI \\ Newborn Intensive Care Units: NICUs \\ Tuberculosis: TB \\ Methicillin-Resistant $S$. aureus: MRSA \\ Intensive Care Unit ward: ICU ward \\ Methicillin-Susceptible S. aureus: MSSA
}

\section{References}

1. Polak JD, Ringler N, Daugherty B. Unit Based Procedures: Impact on the Incidence of Nosocomial Infections in the Newborn Intensive Care Unit. Newborn Infant Nurs Rev. 2004 Mar;4(1):38-45. DOI: 10.1053/j. nainr.2003.12.001

2. Pereira Reginatto F, Silva ISB. The main neonatal dermatological findings: a review. EMJ Dermatol. 2016 Aug;4(1):111-8.

3. Drăgulescu EC, Buzea M, Codiță I. Molecular Analysis of Community-Acquired Staphylococcus aureus strains isolated from Skin and Soft-Tissue Infections in Romania. Romanian Biotechnological Letters. Published online ahead of print. DOI: 10.26327/RBL2017.106

4. The European Committee on Antimicrobial Susceptibility Testing. Breakpoint tables for interpretation of MICs and zone diameters. Version 3.1, 2013. http:// www.eucast.org

5. The European Committee on Antimicrobial Susceptibility Testing. Breakpoint tables for interpretation of MICs and zone diameters. Version 4.0, 2014. http:// www.eucast.org

6. Leclercq R. Mechanisms of resistance to macrolides and lincosamides: nature of the resistance elements and their clinical implications. Clin Infect Dis. 2002 Feb;34(4):482-92. DOI: 10.1086/324626
7. Milheirico C, Oliveira DC, de Lencastre H. Update to the multiplex PCR strategy for assignment of mec element types in Staphylococcus aureus. Antimicrob Agents Chemother. 2007 Sep;51(9):3374-7. DOI: 10.1128/AAC.00275-07

8. Harmsen D, Claus H, Witte W, Rothganger J, Claus $\mathrm{H}$, Turnwald D, et al. Typing of methicillin-resistant Staphylococcus aureus in a university hospital setting by using novel software for spa repeat determination and database management. J Clin Microbiol. 2003 Dec;41(12):5442-8. DOI: 10.1128/JCM.41.12.54425448.2003

9. Murchan S, Kaufmann ME, Deplano A, de Ryck R, Struelens M, Zinn CE, et al. Harmonization of pulsedfield gel electrophoresis protocols for epidemiological typing of strains of methicillin-resistant Staphylococcus aureus: a single approach developed by consensus in 10 European laboratories and its application for tracing the spread of related strains. J Clin Microbiol. 2003 Apr;41(4):1574-85. DOI: 10.1128/JCM.41.4.15741585.2003

10. Tenover FC, Arbeit RD, Goering RV, Mickelsen PA, Murray BE, Persing $\mathrm{DH}$, et al. Interpreting chromosomal DNA restriction patterns produced by pulsedfield gel electrophoresis: criteria for bacterial strain typing. J Clin Microbiol. 1995 Sep;33(9):2233-9.

11. Kluytmans J, van Belkum A, Verbrugh H. Nasal carriage of Staphylococcus aureus: epidemiology, underlying mechanisms, and associated risks. Clin Microbiol Rev. 1997 Jul;10(3):505-20.

12. Boyce JM, Potter-Bynoe G, Chenevert C, King T. Environmental contamination due to methicillin-resistant Staphylococcus aureus: possible infection control implications. Infect Control Hosp Epidemiol. 1997 Sep;18(9):622-7. DOI: 10.1086/502213

13. Albrich WC, Harbarth S. Health-care workers: source, vector, or victim of MRSA? Lancet Inf Dis. 2008 May;8(5):289-301. DOI: 10.1016/S14733099(08)70097-5

14. Rammelkamp CH Jr, Mortimer EA Jr, Wolinsky E. Transmission of streptococcal and staphylococcal infections. Ann Intern Med. 1964 May;60(5):753-8. DOI: 10.7326/0003-4819-60-5-753

15. Mernelius S. Infection control of Staphylococcus aureus - spa typing to elucidate transmission. Thesis. 2015;1-95.

16. Sherertz RJ, Bassetti S, Bassetti-Wyss B. "Cloud" Health-Care Workers. Emerg Infect Dis. 2001 Apr;7(2):241-4. DOI: 10.3201/eid0702.010218

17. Siegel JD, Rhinehart E, Jackson M, Chiarello L, and the Healthcare Infection Control Practices Advisory Committee. 2007 Guideline for Isolation Precautions: Preventing Transmission of Infectious Agents in Healthcare Settings https://www.cdc.gov/infectioncontrol/ guidelines/isolation/index.html 
18. Chan GJ, Lee ACC, Baqui AH, Tan J, Black RE. Risk of Early-Onset Neonatal Infection with Maternal Infection or Colonization: A Global Systematic Review and Meta-Analysis. PLoS Medicine. 2013 Aug;10(8):e1001502. DOI: 10.1371/journal. pmed.1001502

19. Remington JS, Klein JO, Wilson ChB, Nizet V, Maldonado YA. Infectious Diseases of the Fetus and Newborn Infant, 7th Edition, by Saunders, an imprint of Elsevier Inc. 2011;1-1273.

20. Folden DV, Machayya JA, Sahmoun AE, Beala JR, Holzmana GS, Helgerson SD, et al. Estimating the proportion of community-associated methicillin-resistant Staphylococcus aureus: two definitions used in the USA yield dramatically different estimates. J Hosp Infect. 2005 Jun;60:329-32. DOI: 10.1016/j.jhin.2004.12.025

21. Otter JA, French GL. Nosocomial transmission of community associated methicillin-resistant Staphylococcus aureus: an emerging threat. Lancet Infect Dis. 2006 Dec; 6(12):753-5. DOI: 10.1016/S1473-3099(06)70636-3

22. Glaser P, Martins-Simões P, Villain A, Barbier M, Tristan A, Bouchier C, et al. Demography and intercontinental spread of the USA300 community-acquired methicillin-resistant Staphylococcus aureus lineage. mBio. 2016 Feb;7(1):e02183-15. DOI: 10.1128/ mBio.02183-15

23. Carrel M, Perencevich EN, David MZ. USA300 Methicillin-Resistant Staphylococcus aureus, United States, 2000-2013. Emerg Infect Dis. 2015 Nov;21(11):1973 -1980. DOI: $10.3201 /$ eid2111.150452

24. Healy CM, Hulten KG, Palazzi DL, Campbell JR, Baker CJ. Emergence of new strains of methicillin-resistant Staphylococcus aureus in a neonatal intensive care unit. Clin Infect Dis. 2004 Nov;39(10):1460-6. DOI: $10.1086 / 425321$

25. Pfaller MA, Herwaldt LA. The clinical microbiology laboratory and infection control: emerging pathogens, antimicrobial resistance, and new technology. Clin Infect Dis. 1997 Jun;25(4):858-70. DOI: 10.1086/515557

26. Azarian T, Cook RL, Johnson JA, Guzman N, McCarter YS, Gomez N, et al. Whole-Genome Sequencing for Outbreak Investigations of Methicillin-Resistant Staphylococcus aureus in the Neonatal Intensive Care Unit: Time for Routine Practice? Infect Control Hosp Epidemiol. 2015 Jul;36(7):777-85. DOI: 10.1017/ ice. 2015.73

27. Edgeworth JD, Yadegarfar G, Pathak S, Batra R, Cockfield JD, Wyncoll D, et al. An outbreak in an intensive care unit of a strain of methicillin-resistant Staphylococcus aureus sequence type 239 associated with an increased rate of vascular access device-related bacteremia. Clin Infect Dis. 2007 Feb;44(4):493-501. DOI: $10.1086 / 511034$

28. Oliveira D, Santos-Sanches I, Mato R, Tamayo M, Ribeiro $G$, Costa $D$, et al. Virtually all methicillin resis- tant Staphylococcus aureus (MRSA) infections in the largest Portuguese teaching hospital are caused by two internationally spread multiresistant strains: the 'Iberian' and the 'Brazilian' clones of MRSA. Clin Microbiol Infect. 1998 Jul;4(7):373-84. DOI: 10.1111/j.14690691.1998.tb00081.x

29. Kuroda M, Ohta T, Uchiyama I, Baba T, Yuzawa $\mathrm{H}$, Kobayashi I, et al. Whole genome sequencing of meticillin-resistant Staphylococcus aureus. Lancet. 2001 Apr;357(9264):1225-40. DOI: 10.1016/S01406736(00)04403-2

30. Diep BA, Gill SR, Chang RF, Phan TH, Chen JH, Davidson $\mathrm{MG}$, et al. Complete genome sequence of USA300, an epidemic clone of community-acquired meticillin-resistant Staphylococcus aureus. Lancet. 2006 Mar;367(9512):731-39. DOI: 10.1016/S01406736(06)68231-7

31. DeLeo FR, Otto M, Kreiswirth BN, Chambers HF. Community-associated meticillin-resistant Staphylococcus aureus. Lancet. 2010 Sep;375(9725):1557-68 DOI: 10.1016/S0140-6736(09)61999-1

32. Boyle-Vavra S, Ereshefsky B, Wang CC, Daum RS. Successful multiresistant community-associated methicillin-resistant Staphylococcus aureus lineage from Taipei, Taiwan, that carries either the novel Staphylococcal chromosome cassette mec (SCCmec) type VT or SCCmec type IV. J Clin Microbiol. 2005 Sep;43(9):471930. DOI: $10.1128 / \mathrm{JCM} .43 .9 .4719-4730.2005$

33. Diep BA, Otto M. The role of virulence determinants in community-associated MRSA pathogenesis. Trends Microbiol. 2008 Aug;16(8):361-9. DOI: 10.1016/j. tim.2008.05.002

34. Krziwanek K, Luger C, Sammer B, Stumvoll S, Stammler M, Metz-Gercek S, et al. PVL-positive MRSA in Austria. Eur J Clin Microbiol Infect Dis. 2007 Dec;26(12):931-5. DOI: 10.1007/s10096-007-0391-4

35. Witte W, Strommenger B, Cuny Ch, Heuck D, Nuebel U. Methicillin-resistant Staphylococcus aureus containing the Panton-Valentine leucocidin gene in Germany in 2005 and 2006. J Antimicrob Chemother. 2007 Dec;60(6):1258-63. DOI: 10.1093/jac/dkm384

36. Nashev D, Bizeva L, Toshkova K. First cases of infections caused by Panton-Valentine leukocidin positive community-acquired methicillin-resistant Staphylococcus aureus in Bulgaria. Euro Surveill. 2007 Jun;12(26):pii=3225.

37. Daskalaki M, Rojo P, Marin-Ferrer M, Barrios M, Otero JR, Chaves F. Panton-Valentine leukocidin-positive Staphylococcus aureus skin and soft tissue infections among children in an emergency department in Madrid, Spain. Clin Microbiol Infect. 2010;16(1):74-77. DOI: 10.1111/j.1469-0691.2009.02830.x

38. Orendi JM, Coetzee N, Ellington MJ, Boakes E, Cookson BD, Hardy KJ, et al. Community and nosocomial transmission of Panton-Valentine leucocidin-positive 
community-associated meticillin-resistant Staphylococcus aureus: implications for healthcare. J Hospital Infect. 2010 Jun;75(4):258-64. DOI: 10.1016/j. jhin.2010.03.023

39. Sanchini A, Spitoni MG, Monaco M, Raglio A, Grigis A, Petro W, et al. Outbreak of skin and soft tissue infections in a hospital newborn nursery in Italy due to community-acquired meticillin-resistant Staphylococcus aureus USA300 clone. J Hospital Infect. 2013;83:3640. DOI: 10.1016/j.jhin.2012.09.017

40. Kaïret K, Ho E, Van Kerkhoven D, Boes J, Van Calenbergh S, Pattyn L, et al. USA300, A strain of community-associated methicillin-resistant Staphylococcus aureus, crossing Belgium's borders: outbreak of skin and soft tissue infections in a hospital in Belgium. Eur J Clin Microbiol Infect Dis. 2017 May;36(5):905-9. DOI: $10.1007 / \mathrm{s} 10096-016-2883-6$

41. Sassi M, Felden B, Revest M, Tattevin P, Augagneur Y, Donnio P-Y. An outbreak in intravenous drug users due to USA300 Latin-American variant community-acquired methicillin-resistant Staphylococcus aureus in France as early as 2007. Eur J Clin Microbiol Infect Dis. 2017 Dec;36(12):2495-501. DOI: 10.1007/ s10096-017-3092-7

42. Huang E, Gurzau AE, Hanson BM, Kates AE, Smith TC, Pettigrew MM, et al. Detection of livestock-associated methicillin-resistant Staphylococcus aureus among swine workers in Romania. J Infect Public Health. 2014 Jul-Aug;7(4):323-32. DOI: 10.1016/j.jiph.2014.03.008

43. Szekely E, Enache LS, Marinescu S, Ungvari E, Toth A, Paszti J. Fatal sepsis due to community-associated methicillin resistant Staphylococcus aureus - a case report. Rev Rom Med Lab. 2010 Jun;18(2/4):29-33.

44. Alexandrescu V, Codiță I, Băețel A, Drăgulescu E-C, Coldea I-L. Caz letal de gripă sezonieră suprainfectată cu S. aureus rezistent la meticilină producător de leucocidină Panton-Valentine - România, 2009 [Engl. Seasonal flu fatal case superinfected with Methicillin-Resistant S. aureus producing Panton-Valentine Leukocidin - Romania, 2009]. Bacteriol Virusol Parazitol Epidemiol. 2010 Apr-Jun;55(2):107-108.

45. Ionescu B, Ionescu D, Gheorghe I, Curuțiu C, Banu O, Bleotu C, et al. Virulence patterns of Staphylococcus aureus hospital strains isolated in Bucharest, Romania. Rom Biotech Letters. 2015 May-Jun;20(3):10536-46.

46. Vremeră T, Iancu LS, Năstase EV, Logigan C, Miftode EG, Mereuță AI, et al. Triplex real-time PCR for detection of methicillin-resistant Staphylococcus aureus and Panton-Valentine leukocidin in North-East Romania. Rev Med Chir Soc Med Nat Iasi. 2012 OctDec;116(4):1171-6.

47. Vremeră T, Iancu LS, Logigan C, Năstase E, Miftode E, Enache E, et al. Use of real time PCR for testing Staphylococcus aureus isolates from the Iasi Infectious Diseases Hospital. Rev Med Chir Soc Med Nat Iasi.
2011 Jul;115(3):927-33.

48. Dorobăț OM, Bădicuț I, Tălăpan D, Tenea C, Rafila A. Antibiotic resistance of Gram-positive cocci isolated in 2008. Bacteriol Virusol Parazitol Epidemiol. 2010 AprJun;55(2):83-92.

49. Ionescu R, Mediavilla JR, Chen L, Grigorescu DO, Idomir M, Kreiswirth BN, et al. Molecular Characterization and Antibiotic Susceptibility of Staphylococcus aureus from a Multidisciplinary Hospital in Romania. Microb Drug Resist. 2010 Dec;16(4):263-72. DOI: 10.1089/mdr.2010.0059

50. Kock R, Becker K, Cookson B, Van Gemert-Pijnen JE, Harbarth S, Kluytmans J, et al. Methicillin-resistant Staphylococcus aureus (MRSA): burden of disease and control challenges in Europe. Euro Surveill. 2010 Oct;15(41):19688. DOI: 10.2807/ese.15.41.19688-en

51. Năstase E, Dorneanu O, Vremeră T, Logigan C, Miftode E, Dorobăț CM. MecA and pvl genes detection in Staphylococcus aureus strains isolated from lower respiratory tract infections. Rev Med Chir Soc Med Nat Iasi. 2010 Oct-Dec;114(4):1162-8.

52. Nica M, Biolan T, Dascălu A, Mozes E, Toderan A, Calistru P, et al. Bacterial strains isolated from systemic infections and reported for evaluation and antibiotic resistance surveillance by the "Dr. Victor Babes" Clinical Hospital for Infectious and Tropical Diseases, Bucharest. Bacteriol Virusol Parazitol Epidemiol. 2010 Apr-Jun;55(2):161-8.

53. Szekely E, Lorinczi L, Bilca D, Fodor E, Soki J, Sabău M. Incidence, antibiotic resistance and clonal relations of MRSA strains isolated from a Romanian university hospital. Acta Microbiol Immunol Hung. 2008 Mar;55:1-13. DOI: 10.1556/AMicr.55.2008.1.1

54. Dorneanu O, Miftode E, Vremera T, Năstase E, Filip O, Luca V. Prevalence and characteristics of Staphylococcus aureus isolated from infections in Northeast Romania. J Prev Med. 2006 Jun;14(3-4):66-70.

55. Coman G, Cîrlan M, Petraru E, Dahorea C, Butnaru F. Antibiotic resistance phenotypes of S. aureus from pediatric infections. Rev Med Chir. 2002 Jan;106:46-52.

56. Grigore L, Dumitrescu V, Sfartz S, Codiță I. The antibiotic resistance of Staphylococcus aureus strains isolated in units with an elevated nosocomial risk and in outpatient facilities in 1995. Bacteriol Virusol Parazitol Epidemiol. 1997 Jan-Mar;42:51-4.

57. Grundmann H, Aanensen DM, Van den Wijngaard CC, Spratt BG, Harmsen D, Friedrich AW, the European Staphylococcal Reference Laboratory Working Group. Geographic Distribution of Staphylococcus aureus Causing Invasive Infections in Europe: A Molecular-Epidemiological Analysis. PLoS Medicine. 2010 Jan;7(1):e1000215. DOI: 10.1371/journal. pmed. 1000215

58. Oprea M, Drăgulescu EC, Coldea IL, Codiţă I, Szmal C, Străuţ M. Molecular characterization of Staphylo- 
coccus aureus isolates belonging of two most prevalent spa-types recovered from Romanian hospitals during 2006-2007. Clin Microbiol Inf. 2008 May;14 (Suppl. 7):S410-S411.

59. Szekely E, Man A, Mare A, Vas KE, Molnar S, Bilca $\mathrm{D}$, et al. Molecular epidemiology and virulence factors of methicillin-resistant Staphylococcus aureus strains in a Romanian university hospital. Rom Rev Lab Med. 2012 Dec;20(4/4):371-82.

60. Grundmann H, Schouls LM, Aanensen DM, Pluister GN, Tami A, Chlebowicz M, et al, on behalf of the ESCMID Study Group on Molecular Epidemiological Markers and the European Staphylococcal Reference Laboratory Working Group. The dynamic changes of dominant clones of Staphylococcus aureus causing bloodstream infections in the European region: Results of a second structured survey. Euro Surveill. 2014 Dec;19(49):20987. DOI: 10.2807/1560-7917. ES2014.19.49.20987

61. Cîrlan M, Saad M, Coman G, Bilal NE, Elbashier AM, Kreft D, et al. International spread of major clones of methicillin resistant Staphylococcus aureus: nosocomial endemicity of multi locus sequence type 239 in Saudi Arabia and Romania. Infect Genet Evol. 2005 Jan;5:335-9. DOI: 10.1016/j.meegid.2004.09.005

62. Codiţă I, Oprea M, Szmal C, Drăgulescu EC, Traşcă M, Brehar Cioflec D, Chicin G, Şerban R, Pistol A. Panton-Valentine leukocidin positive, t008 spa-type meticillin-resistant Staphylococcus aureus in a Romanian western county hospital. Clin Microbiol Infect. 2008 May; 14 (Suppl. 7):S687.

63. Codiţă I, Drăgulescu EC, Lixandru BE, Coldea IL, Dinu S, Străuț M. Cluster of t127 spa type MRSA strains evolving in a Romanian newborns unit in 2010.
Rom Rev Lab Med. 2011 Jun;Suppl.19 (2/4):S81-2.

64. Franco A, Hasman H, Iurescia M, Lorenzetti R, Stegger M, Pantosti A, et al. Molecular characterization of spa type $\mathrm{t} 127$, sequence type 1 methicillin-resistant Staphylococcus aureus from pigs. J Antimicrob Chemother. 2011 Jun;66(6):1231-5. DOI: 10.1093/jac/dkr115

65. Monecke S, Muller E, Dorneanu OS, Vremeră T, Ehricht R. Molecular Typing of MRSA and of Clinical Staphylococcus aureus Isolates from Iasi, Romania. PLoS ONE. 2014 May;9(5):e97833. DOI: 10.1371/ journal.pone.0097833

66. Scheithauer S, Trepels-Kottek S, Häfner H, Keller $\mathrm{D}$, Ittel $\mathrm{T}$, Wagner $\mathrm{N}$, et al. Healthcare worker-related MRSA cluster in a German neonatology level III ICU: A true European story. Int J Hyg Environ Health. 2014 Mar;217(2-3):307-11. DOI: 10.1016/j. ijheh.2013.07.006

67. Pammi M, Davis RJ, Gordon A, Starke J. Infant isolation and cohorting for preventing or reducing transmission of healthcare-associated infections in neonatal units. Cochrane Db Syst Rev. 2016;12:CD012458.

68. Lepelletier D, Corvec S, Caillon J, Reynaud A, Roze J-Ch, Gras-Leguen Ch. Eradication of methicillin-resistant Staphylococcus aureus in a neonatal intensive care unit: which measures for which success? Am J Infect Control. 2009 Apr;37(3):195-200. DOI: 10.1016/j. ajic.2008.09.024

69. Gerber S, Jones R, Scott M, Price J, Dworkin M, Filippell M, Rearick T, et al. Management of Outbreaks of Methicillin-Resistant Staphylococcus aureus Infection in the Neonatal Intensive Care Unit: A Consensus Statement. Infect Control Hosp Epidemiol. 2006 Feb;27(2):139-45. DOI: 10.1086/501216 